\title{
Growth of juvenile turbot in response to food pellets contaminated by fuel oil from the tanker 'Prestige'
}

\author{
Fran Saborido-Rey ${ }^{1,}{ }^{*}$, Rosario Domínguez-Petit ${ }^{1}$, Javier Tomás ${ }^{2}$, \\ Beatriz Morales-Nin ${ }^{2}$, Alexandre Alonso-Fernandez ${ }^{1}$
}

\author{
${ }^{1}$ Instituto de Investigaciones Marinas (CSIC), Eduardo Cabello 6, 36208 Vigo, Spain \\ ${ }^{2}$ Instituto Mediterraneo de Estudios Avanzados (CSIC/UIB), Miquel Marqués 21, 07190 Esporles, Illes Balears, Spain
}

\begin{abstract}
Juvenile turbot Scophthalmus maximus were kept in captivity and were fed a prepared food contaminated with 5 levels of seawater-accommodated fuel oil, from $2.4 \pm 0.35$ to $48.2 \pm 2.2 \mathrm{mg}$ $\mathrm{g}^{-1}$ food. Oil that had been recovered from that released by the tanker 'Prestige' was used. Fish ( $\mathrm{n}=$ 202) were individually tagged while length and weight were recorded. They were then placed randomly in 6 different tanks (1 control and 5 treatments, 32 to 35 individuals in each. For 6 wk, they were fed 3 times daily. At the end of the experiment, the fish were sacrificed, and length and weight recorded. At the beginning of the experiment, there were no significant differences in fish size and weight among tanks. After the treatment, greater oil concentration significantly reduced growth rate in size and weight. However, probably due to competition, smaller fish did not demonstrate notable growth during the experiment in any tank, while larger fish grew more in the tanks with lower oil concentrations in the food. Increasing oil concentration also reduced food consumption by individual fish. However, the reduced feeding rate alone did not explain the reduced growth rate, which was probably also the result of a major reduction in the ability for food energy conversion.
\end{abstract}

KEY WORDS: 'Prestige' · Fuel oil · Growth reduction $\cdot$ Juvenile turbot $\cdot$ Oil pollution

\section{INTRODUCTION}

In November 2002, the oil tanker 'Prestige' sank after breaking in half $240 \mathrm{~km}$ off the Galician coast (NW Spain), releasing $39700 \mathrm{t}$ of heavy fuel into the marine environment (Prego \& Cobelo-Garcia 2004). Large oil patches and sheens were washed onshore, blackening more than $550 \mathrm{~km}$ of the coast. Years after oil spills such as the 'Exxon Valdez' (USA) and the 'Braer' (UK), among others, research studies have documented the persistence of negative effects of oil on marine fish (Norcross et al. 1996, Marty et al. 1997, Stagg et al. 1998, Brauner et al. 1999, Jewett et al. 2002). Among other effects of crude oil on individual marine fish, somatic growth is reduced in experimental fish and in fish from natural populations exposed to crude oil and/or fed oil-contaminated food or prey (Schwartz 1985, Norcross et al. 1996, Stagg et al.
1998, Omoregie \& Ufodike 2000, Peterson 2001, Birtwell $\&$ McAllister 2002). Nonetheless, cases have been documented where the exposure of fish to the water-soluble fraction of oil did not show any detectable effect on growth or survival. This was the case in a study of pink salmon fry Oncorhynchus gorbuscha surviving to adulthood (Birtwell et al. 1999) and for growth of herring Clupea harengus following the 'Braer' spill (Gallego et al. 1995). Since each oil spill varies in terms of the area affected, the ecosystem, and the biochemical characteristics of the oil, it seems important to replicate experiments for every major oil spill and address the question of its effects on target species.

The tanker 'Prestige' released heavy fuel oil with a low volatile and soluble component, which was persistent in the environment and had low degradation rates (Albaigés \& Bayona 2003). Oil mass balance models 


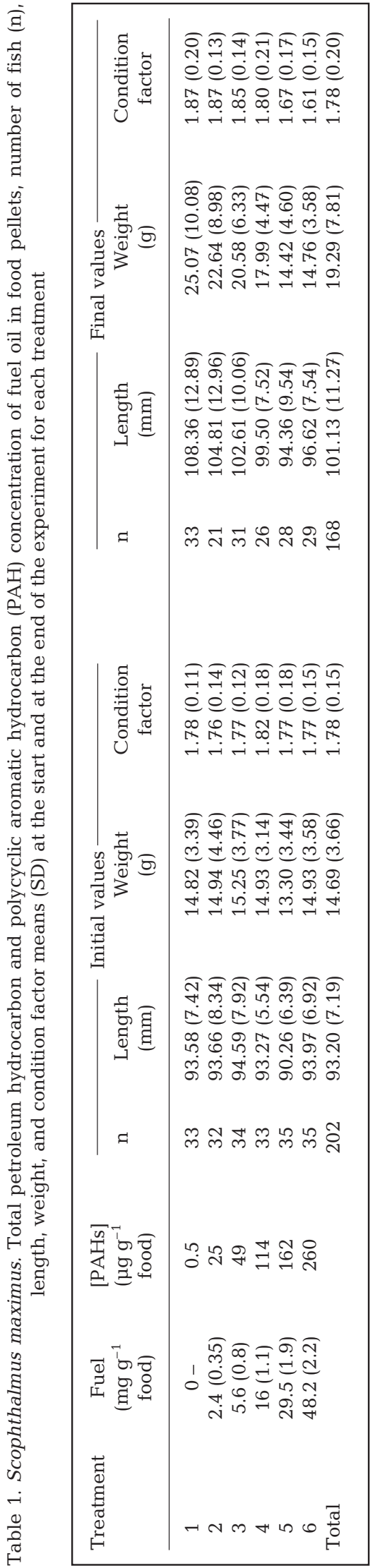

for coastal waters predict a reduction over time in the percent of oil mass on the water surface and an increase in the percent present in the water column (Gin et al. 2001). Eventually, oil dispersion dynamics will result in the accumulation of oil in sea bed sediments as both particulate oil and dissolved oil in pore water (Gin et al. 2001). Thus, among the various species of fish potentially affected by an oil spill in coastal waters, flatfish populations are of major concern because of their close link with the bottom sediments that constitute their habitat (Stagg et al. 1998, Kirby et al. 1999). Both sandy and muddy sediments are prone to trap oil globules, degrading the natural environment of flatfish populations. In addition to the possible contamination of gills and skin by living in a polluted environment, flatfish are also prone to contamination from prey sources (Gin et al. 2001) via the ingestion of oilcontaminated food, as shown for other species (Schwartz 1985, Wang et al. 1993, Carls et al. 1996).

In this study, the potential effects of the 'Prestige' oil spill on the growth of demersal fish were experimentally evaluated on juvenile turbot Scophthalmus maximus. The fish were fed dry food contaminated with various concentrations of fuel oil from the 'Prestige' spill. Due to the high density of the oil and to the origin of the oil used (recovered from the sea), the volatile and soluble components were not present in the fuel. Thus, the effect upon the experimental fish came about through the diet without additional contribution from dissolved contaminants in the water column.

\section{MATERIALS AND METHODS}

A total of 202 juvenile turbot, ranging from 75 to $135 \mathrm{~mm}$ in total length, were collected from a commercial hatchery on June 2004 and transported to the facilities at the Institute of Marine Research in Vigo. Fish were randomly distributed among six 250 l cylindrical aerated tanks. Each tank received approximately 21 $\mathrm{h}^{-1}$ of flow-through, sand-filtered seawater at ca. $18^{\circ} \mathrm{C}$, with a $12 \mathrm{~h}$ light:12 h dark photoperiod. Fish were allowed to acclimate for $10 \mathrm{~d}$ under these conditions before the experiment was started. The fish were fed a maintenance ration $(15 \pm 0.01 \mathrm{~g})$ of commercial turbot pellets (2 $\mathrm{mm}$ in diameter) 3 times daily during this period.

One week before the start of the experiment, fish were anaesthetised (150 ppm 2-phenoxyethanol), measured (total length, $\mathrm{mm}$ ), and weighed (to the nearest $0.01 \mathrm{~g}$ ). Each fish was tagged with a codified soft VI Alfa tag (Northwest Marine Technology) before being assigned to a tank. The total number of fish, mean weight and length, and condition factor in each tank are shown in Table 1. 
During the experiment, 1 group (Treatment 1) was fed uncontaminated food, while the other 5 treatments (Treatments 2 to 6) were fed food contaminated with different levels of 'Prestige' seawater-accommodated fuel oil (Table 1). The fuel carried by the 'Prestige' corresponds to M-100 (Russian terminology) or Fuel No. 6 (English terminology), which is characterised by a low volatile and soluble component, high density (0.9753), and high viscosity (611 centistokes [cSt] at $50^{\circ} \mathrm{C}$ ); it is thus very persistent in the environment and has a low degradation rate. This fuel shows a clear tendency to mix with seawater, creating a very viscous emulsion. This emulsion, which was obtained from the sea right after the oil spill in November 2002 and was characterised elsewhere (Albaigés \& Bayona 2003), was kept in the dark at $4^{\circ} \mathrm{C}$ until use in this experiment (18 mo later). No dispersants were used during the oil spill.

Food pellets, in $140 \mathrm{~g}$ batches, were contaminated by mixing them with fuel oil previously dissolved in dichloromethane carrier. The solvent was then removed in a rotary evaporator followed by mild heating for at least $1 \mathrm{~h}$ in a conventional oven at $50^{\circ} \mathrm{C}$. Contaminated food was prepared weekly, and the 6 batches of food (5 contaminated and 1 untreated) were stored in a refrigerator $\left(4^{\circ} \mathrm{C}\right)$ in sealed Teflon bottles. The fuel concentrations in the pellets were determined at the end of the experiment for each week and batch of food. Fuel oil was extracted from 1 to $2 \mathrm{~g}$ of food with dichloromethane. Because this method extracts other components from the pellets (such as lipids), uncontaminated food (control) was also treated with dichloromethane in the same manner. Since fuel was not added to controls, mean control concentrations were subtracted from all other treatments to arrive at the fuel concentrations. Seawater-accommodated heavy fuel oil composition may change over time largely through alteration of polycyclic aromatic hydrocarbon (PAH) concentration. The 'Prestige' fuel oil was particularly rich in PAHs, which represented $50 \%$ of the total hydrocarbon content in the fuel (Albaigés \& Bayona 2003). PAHs in contaminated and control food pellets were analysed by gas chromatography-mass spectrometry (GC-MS). Details of the analyses performed are given in Martin-Skilton (2006).

The fish were fed this food for $40 \mathrm{~d}$ at a ration of $15.01 \pm 0.02 \mathrm{~g}$ per day and treatment (tank), 3 times daily $(4.7,5.6$ and $4.7 \mathrm{~g}$ at 08:30, 13:30, and 18:30 h, respectively). The estimation of daily ration was based on providing food weight above $3 \%$ of the total biomass in each tank. Excess food was removed once daily immediately after the second dose. Uneaten pellets were retrieved from the bottom by sucking them gently into microperforated plastic bags. Uneaten pellets still maintained the normal consistency and were not contaminated with faeces. Once the pellets were retrieved, they were drained for $1 \mathrm{~h}$. Before weighing they were dried in a conventional oven at $35^{\circ} \mathrm{C}$ for $24 \mathrm{~h}$. The difference between the food provided and the food removed was used as an index of the ingested food. Temperature was recorded 3 times daily in each tank, during the feeding period. After each feeding period, fish were counted and dead fish were removed immediately.

At the end of the experiment, each surviving fish was anaesthetised by immersion in 150 ppm of 2-phenoxyethanol and drained on laboratory paper, and length and weight were recorded. Fish were identified using the individual tag code. Growth rate in length and weight were computed as the percent body length and weight increment during the experiment. Individual condition factor $(K)$ was estimated before and after the experiment according to the following equation:

$$
K=\frac{W}{L^{3}} \times 100
$$

where $W$ and $L$ are total weight $(\mathrm{g})$ and length (mm), respectively.

Analysis of variance (ANOVA) was used to ensure that length, weight, and condition factor among treatment tanks were not statistically different at initial conditions. Because the experimental design lacked replication of treatments, a single linear regression model was fit between the treatment fuel oil concentration as a continuous variable and the growth rate (in length and weight) and condition factor as response variables. This statistical analysis tests whether the observed treatment effects (growth rates) are the result of the nominal treatment factor (i.e. contaminated food) or are unintended side-effects of the procedures (i.e. the tanks) used to impose treatments on the experimental units (Hurlbert 2004). Growth rate was determined for each individual as the percentage difference in length and weight between the end and the beginning of the experiment. Variation in condition factor was also determined for each individual as the difference in $K$ between the end and the beginning of the experiment. A mean growth rate and change in $K$ was then estimated in each treatment. ANOVA was used to compare length, weight, and condition factor within treatments before and then again after the treatment. Length-weight relationships at initial conditions were compared with analysis of covariance (ANCOVA), while the influence of fuel oil concentration was evaluated by fitting a simple linear regression model between the treatment fuel oil concentration and the allometric coefficients of the length-weight power equations estimated at the end of the experiment. Similarly, the effect of the individual initial weight on individual growth performance was examined by first fitting a linear regression model within each treatment; 
the slopes of these lines were then regressed with fuel oil concentration. Factorial ANOVA was used to test differences in temperature among days and tanks. Finally, ANOVA was also used to compare mean food ingested within treatments over the duration of the experiment. All statistical tests were performed using Statistica (StatSoft).

\section{RESULTS}

Table 1 gives the PAH content in the food pellets after GC-MS analysis. The total PAHs presented are the sum of fluorene, phenanthrene, anthracene, fluoranthene, pyrene, benzo[a]anthracene, chrysene, benzo[b]fluoranthene, benzo[k]fluoranthene, benzo[a]pyrene, indene-pyrene, benzo[g,h,i]perylene and dibenzo[ah]anthracene, C1, C2 and C3 alkylated napththalenes, fluorenes and phenanthrenes, and C1 and C2 alkylated pyrenes. The average PAH composition in the contaminated food was as follows: $33 \pm 4 \%$ of 2-ring aromatic compounds, $54 \pm 3 \%$ of 3 -ring aromatic compounds, and $12 \pm 1 \%$ of 4 -ring aromatic compounds. Five- and 6-ring aromatic PAHs represented less than $1 \%$ of the total PAH content of the contaminated food. Total PAH concentration in the control pellets was $0.5 \mu \mathrm{g} \mathrm{g}^{-1}$, and the composition was $14 \%$ 2-ring aromatic compounds, $48 \%$ 3-ring aromatic compounds and $25 \%$ 4-ring aromatic compounds. Five- and 6-ring aromatic compounds were below the detection limit. The concentration of PAHs was highly correlated with total fuel oil concentration $(\mathrm{r}=0.994$, $\mathrm{p}<0.0001)$, although the proportion of PAHs in food pellets decreased in comparison with total fuel oil in higher concentration treatments.

Mean weight at the beginning of the experiment was not significantly different among treatment tanks (Table 1; ANOVA, $F=0.75, \mathrm{p}=0.586$ ). Similarly, initial length was not significantly different among treatments (Table 1 ; ANOVA, $F=0.82, p=0.537$ ). The best fit for relationships of length and weight at the beginning of the experiment was given by linear equations. ANCOVA showed no significant differences among treatments of the length-weight relationships at the beginning of the experiment $(F=0.604, p=0.697)$. Similarly, no significant differences were detected in condition factor among treatments (Table 1; ANOVA, $F=1.034, \mathrm{p}=0.399$ ).

Mean length, weight, and condition factor at the end of the experiment are shown in Table 1. Growth rate, both in length and weight, was clearly higher in Treatment 1, decreasing steadily and significantly with increasing oil concentration (Fig. 1) as shown by the high and significant $r^{2}$ of the relationships between mean growth rate and oil concentration

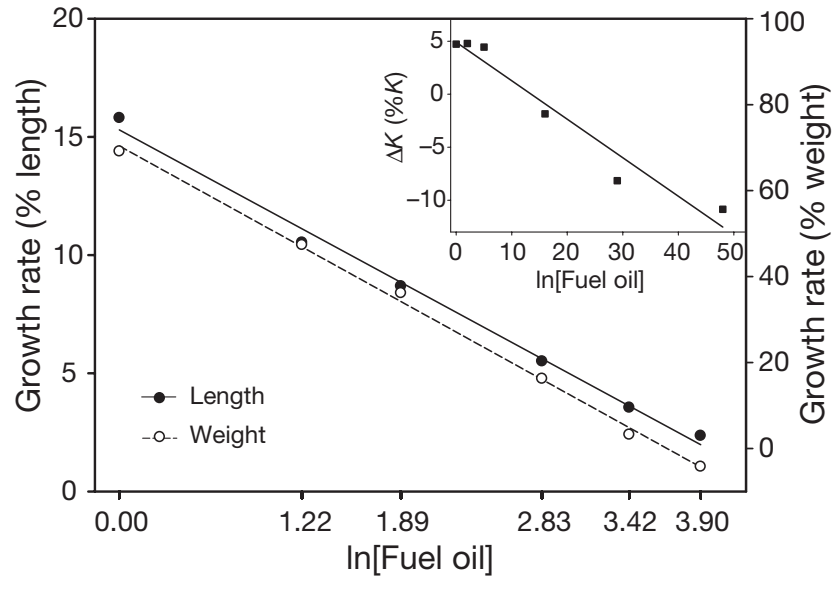

Fig. 1. Scophthalmus maximus. Relationship between oil concentration $(\ln [$ concentration +1$])$ and mean growth rate $(\%$ increase in length [mm] and weight [g]). Inset: Relationship between oil concentration and variation in condition factor $(K)$ before and after treatment

(0.99 at $\mathrm{p}<0.001$ for both parameters). It is remarkable that while control fish increased by $68 \%$ in weight, fish in treatments with the highest fuel concentrations increased only 3\% (Treatment 5) or even lost $4 \%$ of their weight (Treatment 6). ANOVA to compare weight and length within treatments showed that fish in Treatments 1 to 4 significantly increased in both mean weight and length at the end of the experiment (Table 2). However, in Treatments 5 and 6 , the fish did not show significant growth (Table 2). Similarly, change in condition factor $(\Delta K)$ decreased significantly with oil concentration $\left(\mathrm{r}^{2}=\right.$ 0.95, p < 0.001, Fig. 1). Variations in $K$ in Treatments 1 to 3 were positive (ranging between 4.7 and $5.1 \%$ increase relative to initial values) and shifted significantly before and after treatment (Table 2). Fish in Treatment 4, which increased significantly in weight and length, declined in $K$ after treatment (Table 1), but not significantly (Table 2). In contrast, turbot in Treatments 5 and 6 showed significantly lower mean

Table 2. Scophthalmus maximus. Results of ANOVA to compare the mean weight, length, and condition factor within each treatment at the beginning and at the end of the experiment. Significant values in bold

\begin{tabular}{|cccccccc|}
\hline \multirow{2}{*}{ Treatment } & \multicolumn{2}{c}{ Weight } & \multicolumn{2}{c}{ Length } & \multicolumn{3}{c|}{ Condition factor } \\
& $F$ & $\mathrm{p}$ & $F$ & $\mathrm{p}$ & $F$ & $\mathrm{p}$ \\
\hline 1 & 30.67 & $\mathbf{< 0 . 0 1}$ & 32.62 & $\mathbf{< 0 . 0 1}$ & 4.39 & $\mathbf{< 0 . 0 5}$ \\
2 & 10.56 & $\mathbf{< 0 . 0 1}$ & 8.61 & $\mathbf{< 0 . 0 1}$ & 4.69 & $\mathbf{< 0 . 0 5}$ \\
3 & 16.37 & $\mathbf{< 0 . 0 1}$ & 12.25 & $\mathbf{< 0 . 0 1}$ & 5.54 & $\mathbf{< 0 . 0 5}$ \\
4 & 5.15 & $\mathbf{< 0 . 0 5}$ & 8.04 & $\mathbf{< 0 . 0 1}$ & 0.47 & 0.49 \\
5 & 0.20 & 0.658 & 2.31 & 0.134 & 10.78 & $<\mathbf{0 . 0 1}$ \\
6 & 0.47 & 0.494 & 1.40 & 0.240 & 26.86 & $<\mathbf{0 . 0 1}$ \\
\hline
\end{tabular}


$K$ after treatment (Tables 1 and 2). In these 2 treatments, turbot lost an average of 8 and $11 \%$ relative to their initial condition.

Mean weight at the end of the experiment varied significantly among treatments (Table 1; ANOVA, $F=$ 11.42, $\mathrm{p}<0.001)$. Similarly, mean body length was also significantly different among treatments (Table 1; ANOVA, $F=7.59, \mathrm{p}<0.001)$. Comparisons of least significant differences (LSD) in post hoc analysis showed that for both weight and length, no significant differences occurred among adjacent treatments, i.e. those with the closest concentrations. However, significant differences occurred in all other comparisons (Table 3). The best fit for relationships of length and weight at the end of the experiment was given by power equations. The allometric coefficient of power equations was higher in Treatment 1, decreasing significantly with increasing oil concentration (Fig. 2). Allometric coefficients of Treatments 1 to 3 were similar and $>3$, while coefficients for treatments with the highest oil concentration (4 to 6 ) were $<3$, indicating that fish in those treatments increased in weight more slowly than in length.

Fish with small initial weight showed small, no, or even negative growth rates irrespective of the treatment (Fig. 3). Turbot with large initial weight showed a higher increment in Treatment 1, decreasing in the other treatments as oil concentration increased. Thus, in Treatment 6, fish showed no or very little growth, which is reflected in the significantly decreasing slopes with increasing oil concentration (Fig. 2). Therefore, individual growth rate varied both with treatment and initial conditions.

Before the end of the experiment, 34 of 202 fish died (Table 1). Three fish died the day after the tagging, probably as consequence of stress. The other 31 died in the course of the experiment; however, there was no clear pattern in mortality rate among treatments. In Treatment 1 (control), all fish survived. Mortality among the other treatments ranged from 8 to $34 \%$, being the lowest in Treatments 3 and 6 and highest in Treatment 2, which had the lowest oil concentration. Most of the dead fish were those with smaller initial weight in each treatment. Only 4 of 31 dead fish had an initial weight above the initial mean weight of their respective tanks. Half of the fish died between Days 26 and 31 after the start of the experiment. During those days, drastic changes in water temperature were observed (Fig. 4). Water temperature varied considerably during the experiment from 15.5 to $19.5^{\circ} \mathrm{C}$, with the lowest values on Day 6. However, the variation affected all tanks equally, and no significant differences in mean daily temperature among tanks were observed. Factorial ANOVA showed significant differences in mean
Table 3. Scophthalmus maximus. Probability values for the LSD test post hoc comparisons of mean length (above diagonal) and mean weight (below diagonal) among treatments at the end of the experiment. Significant values in bold

\begin{tabular}{|c|c|c|c|c|c|c|}
\hline Treatment & 1 & 2 & 3 & 4 & 5 & 6 \\
\hline 1 & - & 0.218 & $<0.05$ & $<0.05$ & $<0.01$ & $<0.01$ \\
\hline 2 & 0.203 & - & 0.451 & 0.081 & $<0.01$ & $<0.01$ \\
\hline 3 & $<0.01$ & 0.285 & - & 0.257 & $<0.01$ & $<0.05$ \\
\hline 4 & $<0.01$ & $<0.05$ & 0.153 & - & 0.068 & 0.302 \\
\hline 5 & $<0.01$ & $<0.01$ & $<0.01$ & 0.055 & - & 0.408 \\
\hline 6 & $<0.01$ & $<0.01$ & $<0.05$ & 0.081 & 0.849 & - \\
\hline
\end{tabular}

temperature among days $(F=64.9, \mathrm{p}<0,001)$ but not among tanks $(F=1.1, \mathrm{p}=0.369)$, with no interaction $(F=0.1, \mathrm{p}=0.99)$.

Daily per capita food ingested was estimated for each treatment as the difference between the weights of food provided and the food removed from the bottom of the tank divided by the number of surviving fish (Fig. 5). During the first week, before the start of the experiment, there were no significant differences in per capita food ingestion among treatments (ANOVA, $F=1.19, \mathrm{p}=0.329$ ). During the duration of the experiment, there was no significant variation in individual food ingested within Treatments 1, 3, and 5. Turbot in Treatment 2 showed significantly higher ingestion only in Week 7 compared to the other weeks (ANOVA post hoc, p < 0.005 for all comparisons), while fish in Treatment 4 showed significantly lower ingestion in Week 5 only compared to Week 7 ( $p<0.005)$. Fish in Treatment 6 showed significantly lower ingestion in Week 6 only when compared to Week 1 ( $\mathrm{p}<0.005)$; however, a clear decreasing trend was observed for this treatment (Fig. 5). The mean per capita food ingested, in terms of weight, in each tank during the whole

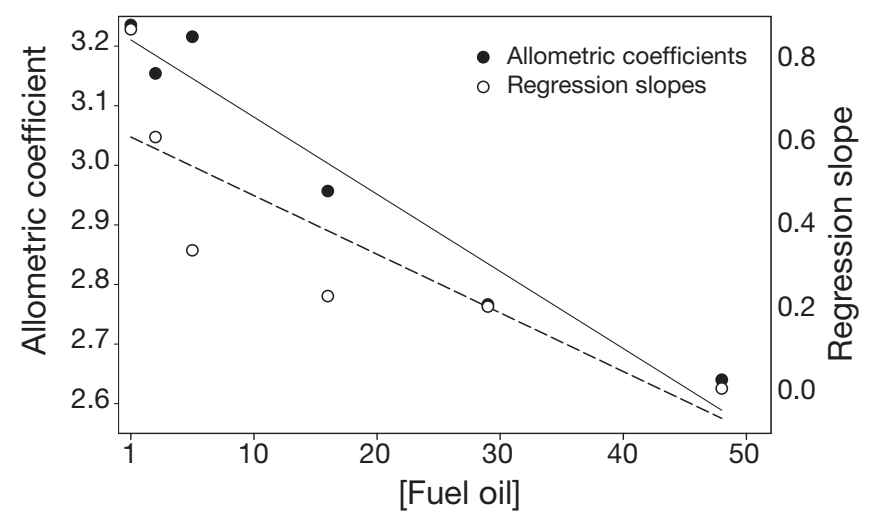

Fig. 2. Scophthalmus maximus. Relationship between oil concentration and $(\bullet)$ the allometric coefficients of the lengthweight power equations estimated at the end of the experiment and (O) the regression slopes between weight increment and initial weight in each specimen for each treatment 

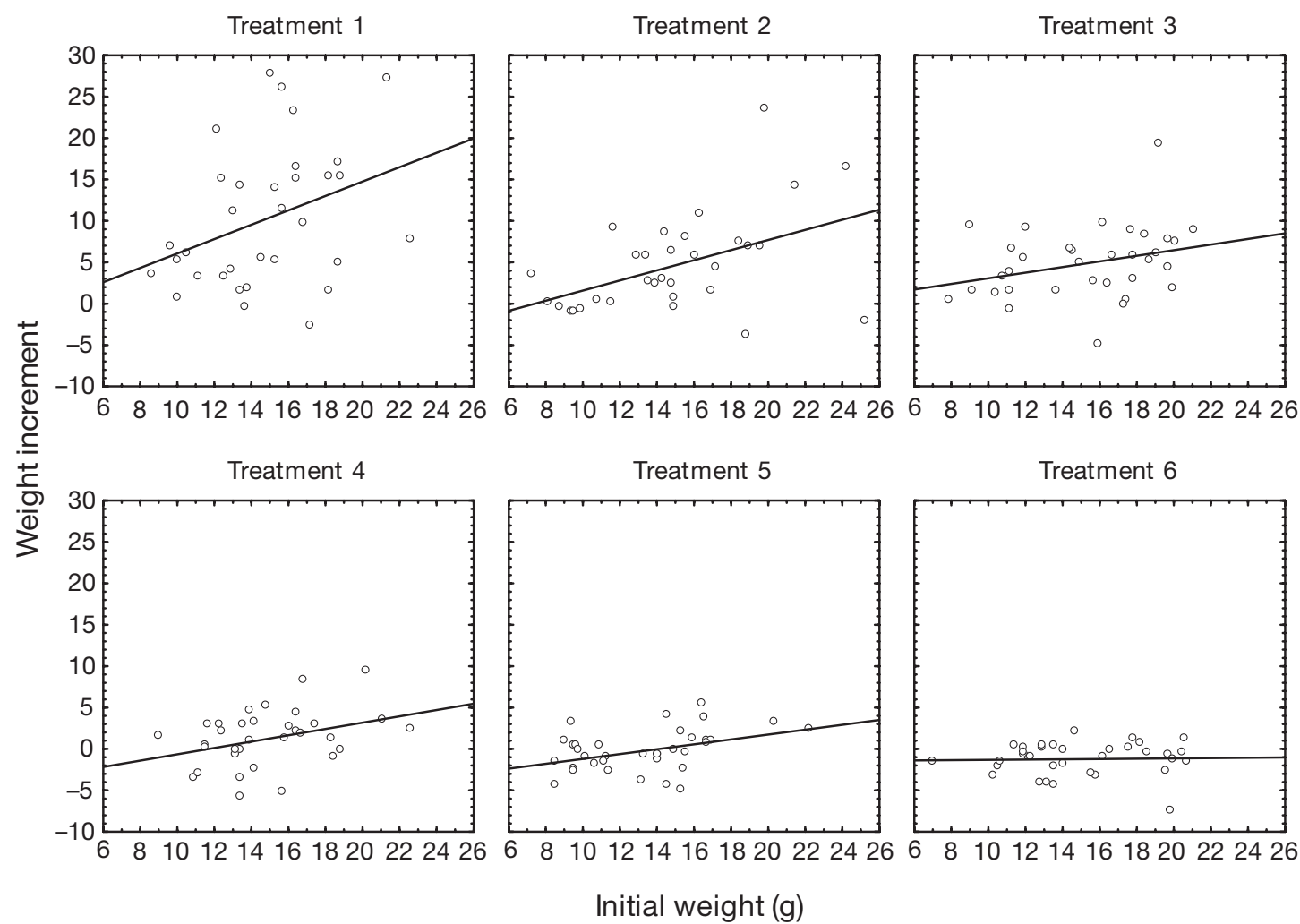

Fig. 3. Scophthalmus maximus. Relationship between weight increment and initial weight in individual fish in each treatment

experiment decreased with oil concentration $\left(\mathrm{r}^{2}=\right.$ $0.88, \mathrm{p}<0.005$; Fig. 5). Similarly, the proportion of food ingested in relation to food provided decreased with oil concentration $\left(\mathrm{r}^{2}=0.80, \mathrm{p}<0.005\right.$; Fig. 5). Food ingested in each treatment showed significant negative effects on growth rate, both in weight $\left(\mathrm{r}^{2}=\right.$ $0.75, \mathrm{p}<0.005)$ and length $\left(\mathrm{r}^{2}=0.67, \mathrm{p}<0.005\right)$.

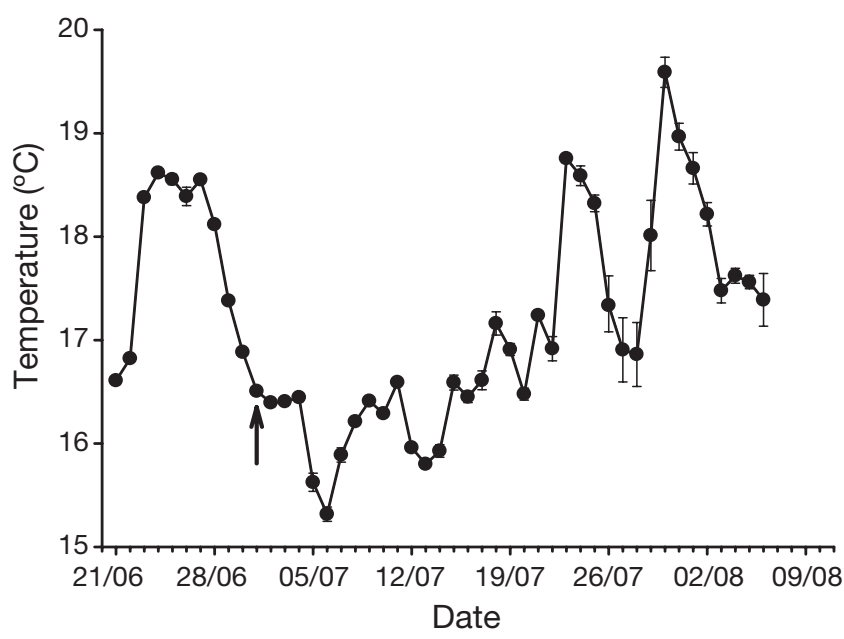

Fig. 4. Mean and standard deviation in daily water temperature during the experiment. Dates given as $\mathrm{dd} / \mathrm{mm}$. Arrow indicates the start day (1 July 2004) of feeding with contaminated food

\section{DISCUSSION}

Several studies have shown that crude oil and its components inhibit growth of fish in a number of species, especially at earlier life stages, such as larvae and juveniles, when the fish are exposed to watersoluble fractions of crude or refined oil (Lindén 1978, Moles et al. 1981, Woodward et al. 1981, Ufodike \& Omoregie 1991, Heintz et al. 2000), oil-laden sediments (Moles \& Norcross 1997), or as a result of ingestion of oil-contaminated food, as in pink salmon fry (Schwartz 1985, Mortensen \& Carls 1994, Carls et al. 1996). The seawater-accommodated fuel oil used in this experiment has been characterised as similar to the original carried by the 'Prestige', proving to be persistent in the environment with low degradation rates (Albaigés \& Bayona 2003, Martin-Skilton 2006), especially due to the low contribution of volatile and soluble components. However, it is unknown to what extent the chemical properties of this emulsion and hence the specific toxicity of the fuel used here may have changed with time at sea.

Somatic growth, although easy to monitor, requires the fish to be exposed a long time before significant differences can be detected (National Research Council 2002). Thus, other sublethal measurements of fish have been used to measure stress and other impacts 


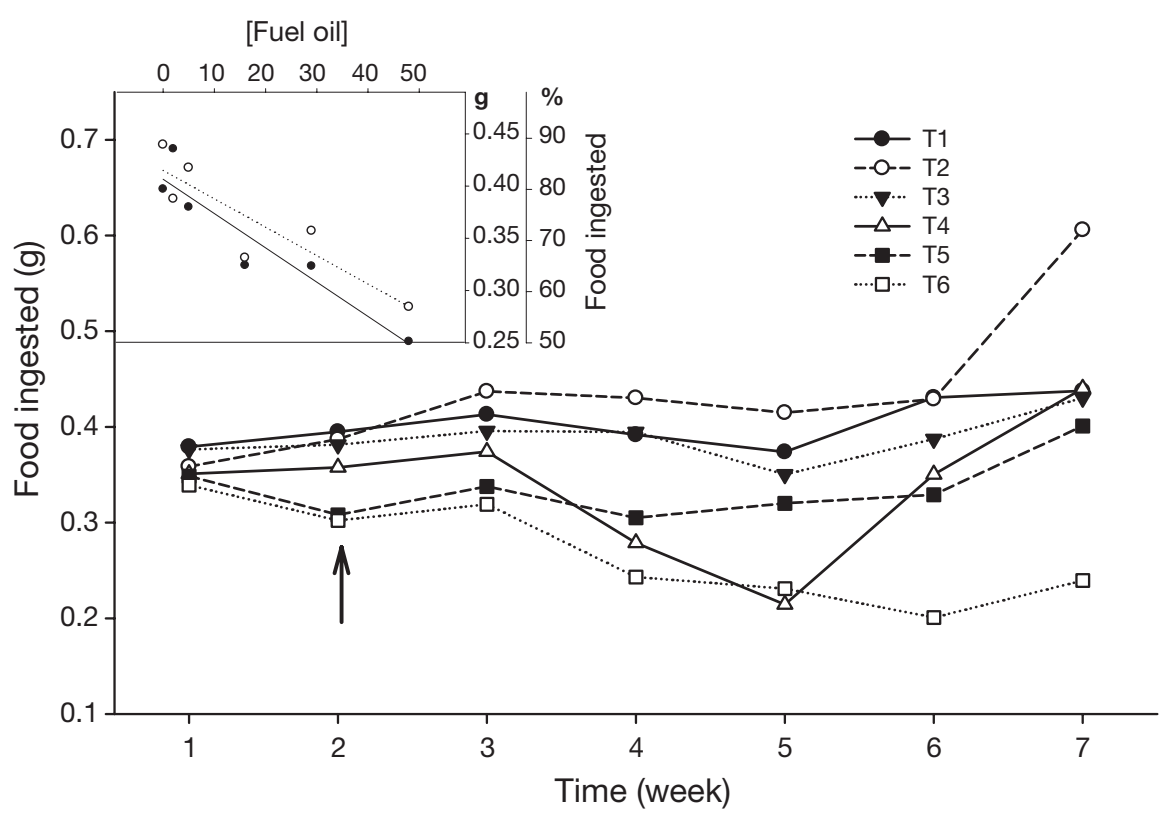

Fig. 5. Scophthalmus maximus. Mean daily food ingested per fish (g) summarised by week and treatment (arrow indicates the start day [1 July 2004] of feeding with contaminated food). Inset: relationship between oil concentration and food ingested for the whole experiment expressed as mean daily weight $(\mathrm{g})$ per fish and proportion (\%) of food provided on fish performance (National Research Council 2002). In our experiment, significant differences in somatic growth, both in length and weight, were detected after $40 \mathrm{~d}$ of providing fish with contaminated food containing 0.25 to $5 \%$ oil. The experimental conditions were adequate for the reared juvenile turbot as shown by the normal growth of the control tank fish both in length and weight (M. Planas pers. comm.). The growth rates in the other fish groups decreased as the level of contamination of the food increased. Growth rates as demonstrated by the length of fish fed contaminated food were 12 to $51 \%$ of those of untreated fish. Weight decreased in the 2 treatments with the highest oil concentration, while the weight gain in the other treatments was 12 to $45 \%$ of that of the untreated fish.

When food was introduced, direct observations showed that fish fed actively in all tanks. However, the fish showed different tendencies in food consumption depending on contaminant level. Control fish and fish fed the 3 lowest concentrations of oil fed normally throughout the study, consuming around $80 \%$ of the food supplied. Feeding on higher concentrations of the fuel oil affected food consumption; thus, fish in Treatment 5 (30 $\mathrm{mg} \mathrm{oil} \mathrm{g}^{-1}$ food) consumed $72 \%$ of the total food supplied, but fish in Treatment 6 (50 $\left.\mathrm{mg} \mathrm{g}^{-1}\right)$ consumed only about $57 \%$. Reduced feeding rate with increasing oil concentration has been observed in other species (Schwartz 1985, Omoregie \& Ufodike 2000). During the last $3 \mathrm{wk}$ of the experiment, fish in Treatment 5 consumed over 1.5 times more food than those in Treatment 6. However, both showed a similar reduction in growth performance. Nevertheless, reduced growth during the first weeks of the experiment will unavoidably lead to lower consumption rates because smaller fish have lower food requirements. The decrease in growth associated with the increase in oil concentration may partially explain the lower feeding rate in those treatments.

Feeding activity, however, was not as strongly correlated with increased oil concentration. Moreover, the decline in food consumption explained $75 \%$ of the observed growth reduction, while oil concentration explained $99 \%$ of this decrease. Thus, the growth reductions shown in this study are probably the result of the decline in feeding activity combined with a major reduction in the ability to convert food energy, i.e. to assimilate food and/or energy. Reduced growth as a consequence of ingesting contaminated prey has also been shown in pink and chum salmon (Wertheimer \& Celewycz 1996, Willette 1996). Reduced energy assimilation can result from alterations to the fish metabolism and tissue after assimilating some of the oil components. Similar effects have been found in 3 species of flatfishes (Moles \& Norcross 1997) after exposure to contaminated sediment. Cellular changes in juvenile salmon were detected as a result of ingesting oil-contaminated food (Wang et al. 1993), decreasing the RNA concentration and hence protein synthesis. Sublethal physiological stress was found in juvenile turbot exposed to water from oil platforms (Stephens et al. 2000). The impact of the water-soluble fraction of fuel oil was absent in our experiment because the fuel used lacked these components. However, fuel oil in faeces and in uneaten food could eventually enter the fish through skin or gills. This potential effect was minimised by cleaning the tanks daily with a high seawater flow $\left(21 \mathrm{~h}^{-1}\right)$ and very low fish density 
(using oversized tanks), which reduced the chances of fish contact with such fuel material. Stocking density was low $\left(0.4 \mathrm{~kg} \mathrm{~m}^{-2}\right)$ compared to experiments conducted on turbot growth performance (Iglesias et al. 1987, Irwin et al. 1999). Hence, the observed growth shifts are likely to be feeding-related.

Feeding on contaminated food did not increase the fish mortality rate during the experiment, even in the high-dose treatments. However, food competition may play an important role in the growth rate, as suggested in this experiment where the larger fish showed larger growth increments. Fish with reduced growth due to contaminated food would be less likely to survive in the field because of their lower capability to compete for food or avoid predators. Additionally, the effects induced by oil ingestion may remain well after the oil is no longer present, including effects on feeding behaviour (Schwartz 1985, Heintz et al. 2000), thus potentially decreasing the survival rate. Irrespective of the fuel concentration, $17 \%$ of the fish provided with contaminated food showed no growth increment in length, but $30 \%$ of the fish lost weight. These percentages rose notably with increasing oil concentration. This difference is reasonable, since a lack of energy intake is normally reflected in weight loss more than in length. This fact is very much reflected in the condition index, which decreased significantly in treatments with the highest oil concentration. Although mortality did not differ among treatments for the duration of the experiment, the decreasing condition index may ultimately reduce the survival rate of those individuals, especially because in similar experiments, low feeding rates were not immediately reversible when oil was removed from the diet (Schwarz 1985).

Care should be used, however, in extrapolating our results to the field. While some of the concentrations used in this study are likely to be found in fish prey after an oil spill, others may be too high. However, we found evidence that the accumulation of some of the oil components through the food web and prey items are likely to affect growth performance. The reduced growth rate is most likely a combination of reduced food ingestion and a sublethal effect of ingesting toxic hydrocarbons that cost energy to depurate (Peterson 2001). This effect can be more acute if oiled sediment is also ingested during feeding (Moles \& Norcross 1997, Freire \& Labarta 2003). In addition, juvenile flatfishes do not avoid areas polluted with oil at low concentrations (Moles et al. 1994). The combination of these features makes flatfish species very vulnerable to oil spills in coastal waters. Reduced growth may considerably impact the recruitment strength and population dynamics, including maturation processes (Heintz et al. 2000).
Acknowledgements. We thank R. Collazo, D. Dominguez, D. Garabana, A. Lysimachou, and R. Martin-Skilton for their help and assistance during the course of the experiment. Thanks also to R. Martín-Skilton and C. Porte from the Environmental Chemistry Department IIQAB-CSIC for providing the results of the PAH analyses on food pellets. Thanks to M. Planas for providing the facilities to run the experiment. This work was sponsored by the Spanish project VEM2003-20081CO2-02.

\section{LITERATURE CITED}

Albaigés J, Bayona JM (2003) El fuel. In: Labarta U, Arias P, Lamela C (eds) La huella del fuel: ensayos sobre el Prestige. Fundación Santiago Rey Fernández-Latorre, A Coruña, p 80-103

Birtwell IK, McAllister CD (2002) Hydrocarbons and their effects on aquatic organisms in relation to offshore oil and gas exploration and oil well blowout scenarios in British Columbia, 1985. Can Tech Rep Fish Aquat Sci 2391:1-52

Birtwell IK, Fink R, Brand D, Alexander R, McAllister CD (1999) Survival of pink salmon (Oncorhynchus gorbuscha) fry to adulthood following a 10-day exposure to the aromatic hydrocarbon water-soluble fraction of crude oil and release to the Pacific Ocean. Can J Fish Aquat Sci 56: 2087-2098

Brauner CJ, Ballantyne CL, Vijayan MM, Val AL (1999) Crude oil exposure affects air-breathing frequency, blood phosphate levels and ion regulation in an air-breathing teleost fish, Hoplosternum littorale. Comp Biochem Physiol 123C:127-134

Carls MG, Holland L, Larsen M, Lum JL, Mortensen DG, Wang SY, Wertheimer AC (1996) Growth, feeding, and survival of pink salmon fry exposed to food contaminated with crude oil. Proc Exxon Valdez Oil Spill Symp. AFS, Bethesda, MD. Am Fish Soc Symp 18:608-618

Freire J, Labarta U (2003). Impactos sobre los recursos y ecosistemas marinos. In: Labarta U, Arias P, Lamela C (eds) La huella del fuel: ensayos sobre el Prestige. Fundación Santiago Rey Fernández-Latorre, A Coruña, p 104-135

Gallego A, Cargill LH, Heath MR, Hay SJ, Knutsen T (1995) An assessment of the immediate effect of the Braer oil-spill on the growth of herring larvae using otolith microstructure analysis. Mar Pollut Bull 30:536-542

Gin KYH, Kamrul Huda M, Kiat Lim W, Tkalich P (2001) An oil spill-food chain interaction model for coastal waters. Mar Pollut Bull 42:590-597

Heintz RA, Rice SD, Wertheimer AC, Bradshaw RF, Thrower FP, Joyce JE, Short JW (2000) Delayed effects on growth and marine survival of pink salmon Oncorhynchus gorbuscha after exposure to crude oil during embryonic development. Mar Ecol Prog Ser 208:205-216

Hurlbert, SH (2004) On misinterpretations of pseudoreplication and related matters: a reply to Oksanen. Oikos 104:591-597

Iglesias J, Olmedo M, Otero JJ, Peleterio JB, Solórzano MR (1987) Growth, under laboratory conditions, of turbot, Scophthalmus maximus, from the Ría de Vigo (north-west Spain). Mar Biol 96:11-17

Irwin S, O'Halloran J, FitzGerald RD (1999) Stocking density, growth and growth variation in juvenile turbot, Scophthalmus maximus (Rafinesque). Aquaculture 178:77-88

Jewett SC, Dean TA, Woodin BR, Hoberg MK, Stegeman JJ (2002) Exposure to hydrocarbons 10 years after the Exxon Valdez oil spill: evidence from cytochrome P4501A expression and biliary FACs in nearshore demersal fishes. Mar Environ Res 54:21-48 
Kirby MF, Neall P, Tylor T (1999) EROD activity measured in flatfish from the area of the Sea Empress oil spill. Chemosphere 38:2929-2949

Lindén O (1978) Biological effects of oil on early development of Baltic herring, Clupea harengus membras. Mar Biol 45: 273-283

Martin-Skilton R (2006) Endocrine disrupters in the marine environment: mechanisms of action and effects in fish. PhD thesis, University of Barcelona

Marty GD, Hose JE, McGurk MD, Brown ED, Hinton DE (1997) Histopathology and cytogenetic evaluation of Pacific herring larvae exposed to petroleum hydrocarbons in the laboratory or in Prince William Sound, Alaska, after the Exxon Valdez oil spill. Can J Fish Aquat Sci 54: 1846-1857

Moles A, Norcross BL (1997) Effects of oil-laden sediments on growth and health of juvenile flatfishes. Can J Fish Aquat Sci 55:605-610

Moles A, Bates S, Rice SD, Korn S. (1981) Reduced growth of coho salmon fry exposed to two petroleum components, toluene and naphthalene, in fresh water. Trans Am Fish Soc 110:430-436

Moles A, Rice S, Norcross BL (1994) Non-avoidance of hydrocarbon laden sediments by juvenile flatfishes. Neth J Sea Res 32:361-367

Mortensen DG, Carls MG (1994) Effects of crude oil ingestion on growth and microstructure of juvenile pink salmon (Oncorhynchus gorbuscha) otoliths. Proc 16th Northeast Pacific Pink and Chum Salmon Workshop, p 183-184

National Research Council (2002) Oil in the sea III: inputs, fates, and effects. National Academy Press, Washington, DC

Norcross BL, Hose JE, Frandsen M, Brown ED (1996) Distribution, abundance, morphological condition, and cytogenetic abnormalities of larval herring in Prince William Sound, Alaska, following the Exxon Valdez oil spill. Can J Fish Aquat Sci 53:2376-2387

Omoregie E, Ufodike BC (2000) Effects of water soluble fractions of crude oil on growth of the Nile tilapia, Oreochromis niloticus (L.). Bull Environ Contam Toxicol 64:601-605

Editorial responsibility: Charles H. Peterson, Morehead City, North Carolina, USA
Peterson CH (2001) The 'Exxon Valdez' oil spill in Alaska: acute, indirect and chronic effects on the ecosystem. Adv Mar Biol 39:1-103

Prego R, Cobelo-Garcia A (2004) Cadmium, copper and lead contamination of the seawater column on the Prestige shipwreck (NE Atlantic Ocean). Anal Chim Acta 524:23-26

Schwartz JP (1985) Effect of oil-contaminated prey on the feeding and growth rate of pink salmon fry (Oncorhynchus gorbuscha). In: Vernberg JF, Thurberg FP, Calabrese A, Vernberg WB (eds) Marine pollution and physiology: recent advances. Belle W. Baruch Library in Marine Science 13, University of South Carolina Press, Columbia, SC, p 459-476

Stagg RM, Robinson C, McIntosh AM, Moffat CF, Bruno DW (1998) The effects of the 'Braer' oil spill, Shetland Isles, Scotland, on P4501A in farmed Atlantic salmon (Salmo salar) and the common dab (Limanda limanda). Mar Environ Res 46:301-306

Stephens SM, Frankling SC, Stagg RM, Brown JA (2000) Sublethal effects of exposure of juvenile turbot to oil produced water. Mar Pollut Bull 40:928-937

Ufodike EBC, Omoregie E (1991) Growth of Oreochromis niloticus niloticus subjected to sublethal concentrations of Gammalin 20 and Actellic 25EC in a continuous-flow toxicant autodelivery system. J Aquat Anim Health 3: 221-213

Wang SY, Lum JL, Carls MG, Rice SD (1993) Relationship between growth and total nucleic acids in juvenile pink salmon Oncorhynchus gorbuscha, fed crude oil contaminated food. Can J Fish Aquat Sci 50:996-1001

Wertheimer AC, Celewycz AG (1996) Abundance and growth of juvenile pink salmon in oiled and non-oiled locations of western Prince William Sound after the 'Exxon Valdez' oil spill. Am Fish Soc Symp 18:518-532

Willette M (1996) Impacts of the 'Exxon Valdez' oil spill on the migration, growth, and survival of juvenile pink salmon in Prince William Sound. Am Fish Soc Symp 18:533-550

Woodward DF, Mehrle PM Mauck WL (1981) Accumulation and sublethal effects of a Wyoming crude oil in cut-throat trout. Trans Am Fish Soc 110:437-445

Submitted: November 24, 2004; Accepted: March 12, 2007 Proofs received from author(s): August 20, 2007 